\title{
MICROHYBRID AND FLOWABLE MICROHYBRID DENTAL RESIN COMPOSITES MEASURED IN FRACTURE TOUGHNESS
}

\author{
Decky J. Indrani, Andi Soufyan, Chairunnisa RR \\ Dept. Of Dental Materials Science Faculty of Dentistry - University of Indonesia
}

\begin{abstract}
Objectives. The aim of this study was to compare the fracture toughness of a microhybrid and a flowable microhyrid resin composites. Methods. Test specimens $(30 \times 15 \times 2) \mathrm{mm}$ made of a microhybrid and a flowable microhybrid were prepared in a double torsion mould and were then polymerized for 20 seconds using a light-curing device. Taken out from the mould, the specimens were than soaked in disfilled water $\left(37^{\circ} \mathrm{C}\right)$ for 1 hour and then fractured in a double-torsion technique. t-Test was used to test significance difference between the microhybrid and flowable microhybrid resin composites. Result. The use of double-torsion technique resulted in crack initition and crack arrest which revealed $\mathrm{K}_{\mathrm{lc}}$ of $1.14 \mathrm{MN} / \mathrm{m}^{3 / 2}$ and $1.045 \mathrm{MN} / \mathrm{m}^{3 / 2}$ for the microhybrid and the flowable microhybrid resin composites, respectively. Both resin composites were insignificantly different in the fracture toughness values showed by t-Test. Conclusions. The present study suggested that there was no significant difference between the microhybrid and the flowable microhybrid resin composites tested. It appreared that filler fraction might not affect the fracture toughness of the resin composties tested.
\end{abstract}

Keywords: fracture toughness, microhybrid composite, flowable composite

\section{Introduction}

Microhybrid resin composites have been widely used in dentistry as posterior restoratives. These resin composites resulted in high viscosity materilas (Knobloch LA, et al, 2002, Bonilla ED, et al, 2001). To fulfill the request of restorative materials useful for pit and fissure sealant or small caries lesions in low bearing areas, a lower viscosity material (Attar N, et al, 2003) were developed i.e flowable resin composites. Althought applied in low stress bearing area, flowable resin composite materials are still subjected to stress applications. There have been several studies on characterizations of low viscosity resin composites. A wide range 
of mechanical and physical properties has been measured for flowable resin composites and the result of study suggested that they should not be used in bulk of high occlusal loading StGeorges, et al (2003) and further reported that flowable resin composites may also be affected by a high-intensity lights in respect to filler fraction. Bonilla, et al (2003) showed fracture toughness for several commercially available flowable composites. According to Bonilla, et al (2003), however, there was no significant difference among 7 of the 9 composites tested and concluded that there was a weak correlation between the filler content by volume and the fracture toughness of these flowable resin composites.

Fracture toughness is defined as a stressintensity factor $(\mathrm{K})$. When the value of $\mathrm{K}$ exceeds the critical value $\left(K_{c}\right)$ for crack growth fracture occurs. The modified UDMA resins increased the fracture toughness of a model flowable composite resin. (Latta Ma, 2008; Kerby RE, 2003). $K_{l c}$ refers to the measured value of stress intensity factor in a mode $\mathrm{I}$ (tensile-opening) (Wantanabe $\mathrm{H}$, et al, 2008; Scherrer SS, et al, 2000). Bonilla, et al (2003) calculated the fracture toughness of flowable resin composites using a single-edge notched beam test. In a double torsion method, the compliance of the specimen is in an early proportional to the crack depth. Several study reported that the double torsion test, provides the most information about crack initiation and propagation and may be the most indicative of the true other fracture of dental resin composites (Latta MA, 2005; Fujishima A and Ferracne JL,1996; Indrani DJ, et al, 1995). The aim of the present study, therefore, was to compare the fracture toughness of a microhybrid with a flowable microhybrid resin composites using a double-torsion technique test.

\section{Materials and Methiods}

The resin composite materials used for the double-torsion specimens were listed in Table 1 below.
Table 1. Materilas used in the present study

\begin{tabular}{|l|l|l|}
\hline Materials & Supplier & Batch No \\
\hline CharmFlo ${ }^{\circledR}$ & DentKist, Korea & 1103047 \\
\hline CharmFil ${ }^{\circledR}$ & DentKist, Korea & 1103047 \\
\hline
\end{tabular}

The double-torsion specimen (Indrani DJ, et.al 1995; Cook and Moopnar, 1990) was a rectangular plate of CharnFlo® (microhybrid) and CharmFil ${ }^{\circledR}$ (flowable microhybrid), prepared in a split stainless steel mold of $30 \times 15 \times 2 \mathrm{~mm}$ containing a $0.6 \mathrm{~mm}$ groove as crack guide along the center of one major surface. Photo polymerization was conducted by irradiating the surface of the resin composite specimens with a blue visible light. After the polymerization, the double-torsion specimen (Fig. 1) was taken out from the double-torsion mold by splitting the mold. A $5 \mathrm{~mm}$ pre-crack was made at the end of the specimen into one edge of the preformed groove, initially by means of a fretsaw and then by a $12 \mu \mathrm{m}$ thick diamond cutting disc. The fracture toughness was measured on a doubletorsion test rig (Fig.1) and fractured with a universal testing machine (Universal Testing Machine, Shimadzu ${ }^{\circledR}$, JAPAN) under a constant crosshead speed of $0.1 \mathrm{~mm} / \mathrm{min}$ at $28^{\circ} \mathrm{C}$.
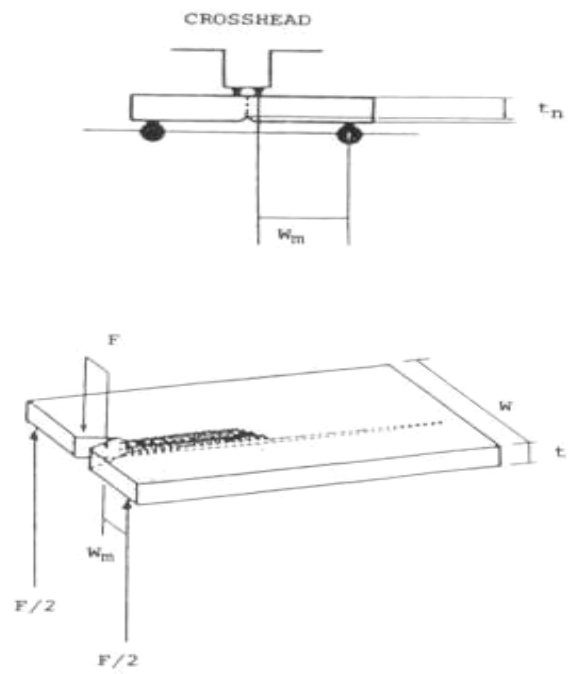

Fig.1. End projection of the double-torsion technique and the specimen (test piece) diagram. 
$\mathrm{K}_{\mathrm{lc}}$ was obtained as the average of six specimens using the equation (Indrani DJ, et.al, 1995; Cook and Moopnar, 1990) below

$$
\mathrm{K}_{\mathrm{lc}}=\mathrm{FW_{ \textrm {m } }} \sqrt{\frac{1+\mathrm{V}}{\mathrm{Wt}^{3} \mathrm{t}_{\mathrm{n}} \mathrm{k}}}
$$

where $\mathrm{K}_{\mathrm{lc}}$ was the $\left(\mathrm{MN} / \mathrm{m}^{3 / 2}\right), \mathrm{W}_{\mathrm{m}}$ was the length of the moment arm (the distance between the central loading points and the outside rollers, $5.7 \mathrm{~mm}), \mathrm{W}$ was the width of the specimen (15 $\mathrm{mm}), \mathrm{t}$ was the thickness of the specimen $(\mathrm{mm})$, $t_{n}$ was the thickness of the plate in the groove, $k$ is the dimension correction factor $(0.277$ for the present geometry; Young and Beaumont, 1977), $\mathrm{v}$ is Poisson's ratio (approximated as 0.3), and $\mathrm{F}$ was the average value of the force maxima $(\mathrm{N})$ obtained from the force-displacement trace.

Independent Sample t-Test were used to test for significant differences in fracture toughness between the CharnFlo ${ }^{\circledR}$ (microhybrid) and CharmFil ${ }^{\circledR} \quad$ (flowable microhybrid) dental resin composites. When the difference between the means of the groups was the same or smaller than the Standard Deviation, it was considered as significantly different.

\section{Results}

$F$ obtained from the force-displacement trace was a follows

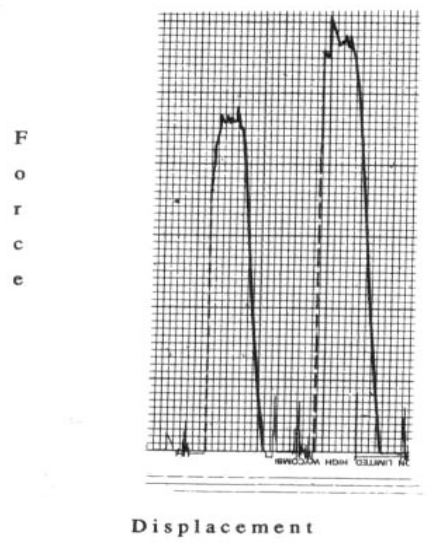

Fig. 2 Typical force-displacement traces of fracture toughness for both microhybrid and flowable microhyrid resin composite specimens.
The fracture toughness result with the Standard Deviations are presented in Fig. 3. The t- Test indicated insignificant difference between the CharnFlo (microhybrid) and CharmFil (flowable microhybrid) dental resin composites.

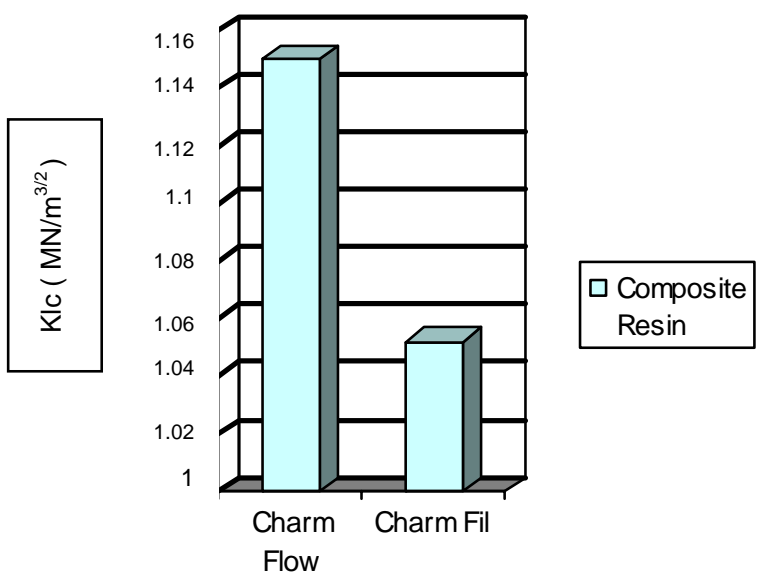

Fig.3. Fracture toughness obtained from CharnFlo (microhybrid) and CharmFil (flowable microhybrid) dental resin composites.

\section{Discussions}

The double-torsion technique was chosen for the present study because of the simple loading geometry. The value of the $\mathrm{K}_{\mathrm{lc}}$ is independent of the crack length which makes for easy use. The length of the test piece also means that the crack can be followed over a distance, which makes it suitable for the study of crack growth and propagation. In addition, it allows good control of crack propagation in the specimen ( Shih and Opoku, 1979; Kinlock and Young, 1983), and it measured $\mathrm{K}_{\mathrm{lc}}$ is on a natural crack.

With the use of a double-torsion test rig (Fig.2) under the application of a universal testing machine, flaws within the CharnFlo ${ }^{\circledR}$ (microhybrid) and CharmFil ${ }^{\circledR}$ (flowable microhybrid) dental resin composite materilas may lead to a formation of a sharp microcracks located deep within the materials which may enlarge and propagate ( Kinloch and Young, 1983) around a sharp crack. The fracture 
toughness force-displacement trace during crack propagation (Fig.2) of the CharmFlo ${ }^{\circledR}$ (flowable microhybrid) and CharmFil ${ }^{\circledR}$ (microhybrid) dental resin composite materilas demonstrated a saw-tooth shape. A mechanism for stick-slip behavior, as proposed by Gledhill and Kinlock (1975), occured as a result of loading the CharmFlo® (flowable microhybrid) or the CharmFil ${ }^{\circledR}$ (microhybrid) dental resin composites at a constant and relatively low rate; an initially sharp crack gradually blunts the resin as the tip deforms. As the load continues to increase, blunting continues untill eventually a new, sharp crack is initiated at the tip of the blunt crack. At its formation this new sharp crack has a small crack tip radius and thus subjected to $K_{l}$ much greater than the $K_{l c}$ appropriate to its propagation. A stick-slip behavior (Kinlock and Young, 1983) indicated a critical stress intensity factor for crack initiation $\left(\mathrm{K}_{\mathrm{lc}}\right)$ and crack arrest $\left(\mathrm{K}_{\mathrm{ca}}\right)$. An average of the small differences between $\mathrm{K}_{\mathrm{ci}}$ and $\mathrm{K}_{\mathrm{ca}}$ was used to determine $\mathrm{K}_{\mathrm{lc}}$ as in the previous work of Fujishima A and Ferracane JL (1996), Indrani DJ, et.al, (1995) and Cook and Moopnar (1990).

Although having a low viscosity, the flowable microhybrid resin composite in the present study demonstrated $\mathrm{K}_{\mathrm{lc}}$ insignificantly different fracture toughness than that from the microhybrid one. It was probably because of the high ratio of resin/filler component in CharmFlo ${ }^{\circledR}$ (flowable microhybrid) than that in Charmfil (microhybrid). It seemed that CharmFlo ${ }^{\circledR}$ (flowable microhybrid) resin composite, which has a high elastic modulus, tended to blunt the sharp crack more than the lower elastic modulus one, the Charmfil (microhybrid), did.

The magnitude of the fracture toughness of Charmflow microhybrid resin composite from this study can be compared with that obtained from Bonilla, et.al (2003). The closest match value of $K_{\mathrm{lc}}$ was the highest value of $1.15 \mathrm{MN} / \mathrm{m}^{1.5}$ from the present study compared to the lowest value of $1.146 \mathrm{MN} / \mathrm{m}^{1.5}$ from Bonillla et.al (2003). This was probably due to a different polymerization time; the specimens in the present study were photocured at a shorter time i.e. 20 seconds than that in the study of
Bonilla, et al (2003) to which 45-minutes curing was used due to additional cure.

\section{Conclussion}

It has been shown from this study that there was a very weak correlation of fracture toughness between the microhybrid the flowable microhybrid dental resin composites tested

\section{Refferences}

1. Knobloch LA, et al, (2002). Fracutre toughness of packable and convensional composite materials. J Prost Dent 88(3): 307-313.

2. Bonilla Esteban D, Mardirossian G, Caputo AA (2001). Fracture toughness of posterior resin composites. Quintessence Int 32(3): 206-210.

3. Attar N, et al, (2003). Flow, strength, stiffness and radiopacity of flowable resin composites.

4. St-George AJ, Swift EJ, Thompson JY, Heymann HO (2003). Irradiance effects on the mechanical properties of universal hybrid and flowable hybrid resin composites. Dental Materials 19(5) : 406-413.

5. Bonilla Esteban D, Yashar Mahrokh, Caputo Angelo A (2003). Fracture toughness of nine flowable resin composites. The Journal of Prosthetic Dentistry; 89(3) : 261-267.

6. Latta MA, Gross S, Wertzberger B (2005). Fracture Toughness of UDMA based Dental Composites. AADR $37^{\text {th }}$ Annual Meeting and Exhibition.

7. Kerby RE, Tiba AL., Knobloch A, Schricker SR, Tiba O (2003). Fracture toughness of modified dental resin systems. Journal of Oral Rehabilitation 30 (8): 780 - 784.

8. Watanabe H, Khera, Satish SC; Vargas MA, Qian F (2008). Fracture toughness comparison of six resin composites. Dental materials; 24 (3): 418-25.

9. Scherrer SS, Botsis J, Studer M, Pini M, Wiskott HWA, Belser C (2000). Fracture toughness of aged dental composites in combined mode I and mode II loading. Journal of Biomedical Materials Research 53 (4): 362-370.

10. Indrani Decky, Cook WE, Televantos MS, Tyas, MJ, Harcourt JK, (1995). Fracture Toughness of Water-aged Resin compsites Restorative Materials. Dental Materials 11:201-207. 
11. Cook and Moopnar (1990). Influence of chemical structure on the fracture behaviour of dimethacrylate composite resins. Biomaterials 11: 272-276.

12. Young RJ and Beaumont PWR, (1977). Failure of brittle polymers by slow crack growth Part3: Effect of composition upon the fracture of $\mathrm{Si}$ particle-filled epozy resin composites. J Mat Sci 12: 684-692.
13. Shih TT, Opoku J, (1979). Application of fracture mechanics to ceramic materials - a state of the art review. Eng Fract Mech 12:479-498.

14. Kinlock AJ and Young RJ, (1983). Fracture behaviour of polymers. London; CRC Pub 3: 74-93.

15. Gledhill and Kinlock (1975). Crack Growth in wpoxy resin adhesive. J Mat Sci 5: 1261 